\title{
Andrographolide Induced Succinate Dehydrogenase Activity in Isolated Mitochondrial Fractions from Different Organ of BALB/C Mice
}

\author{
H. K. Garg \& Ashish Shrivastava* \\ Department of Zoology \& Biotechnology, Govt. Motilal Vigyan Mahavidyalaya, Bhopal - \\ 462008 (India), * Department of Biotechnology, C.S.A. Govt. P. G. College Sehore - 466001 (India)
}

\begin{abstract}
Andrographolide, a bicyclic diterphenoid lactose, extracted from a plant, Andrographis paniculata, is known for its multiple clinical applications in traditional Siddha and Ayurvedic systems in India. Its therapeutic value is perhaps by virtue of its mechanism of action through enzyme induction. The present study is aimed to determine the effects of andrographolide on succinate dehydrogenase (SDH) activity, in vitro, using mitochondrial fractions isolated from different organs of $B A L B / c$ mice. Administration of andrographolide into mitochondrial fraction of liver, lung and kidney resulted in the induction of SDH. Mitochondrial fraction of lung tissues indicated the maximum SDH acceleratory activity (68.19\%), in vitro, against $50 \mu \mathrm{g} / \mathrm{ml}$ concentration of andrographolide.
\end{abstract}

Keywords : Andrographolide, Succinate dehydrogenase, 2,6-dichlorophenol-indophenol, Mitochondrial fraction.

\section{Introduction}

Andrographis paniculata commonly known as Nilavembu is an annual herb, found, in wild, throughout the plains of India especially Tamil Nadu, Karnataka, Maharashtra, Orissa and Uttar Pradesh. The plant species is known for its therapeutic properties viz. Anti-diarrhoeal, anti-inflammatory, anti-choleric, immuno-stimulant and also anti-malarial, anti-hypertensive, antipyretic, anti-thrombotic and hepato-protective (Agrawal, 1997).

Mitochondria enclose the biochemical machinery for cellular respiration; the aerobic processes by which sugars, fatty acids, and amino acids are broken down into carbon dioxide \& water and their chemical energy is entrapped as ATP. The Kreb's cycle, also called tri-carboxylic acid or citric acid cycle, is a key series of reactions in this aerobic process. The mitochondrial succinate dehydrogenase (SDH) complex catalyses the oxidation of succinate to fumarate in the Kreb's cycle and feeds electrons to the respiratory chain ubiquinone (UQ) pool (Tzagoloff, 1982). Succinate - fumarate reaction is measured by monitoring the reduction of an artificial electron acceptor, 2, 6-dichlorophenolindophenol (DCIP). DCIP is supplied as a dark blue solution and it gets lighter \& lighter and finally becomes colourless when reduced. As the solution becomes lighter the absorbance at $600 \mathrm{~nm}$ decreases gradually. In order to use an artificial electron acceptor, the normal path of electrons in the electron transport chain (ETC) must be blocked. This is accomplished by adding sodium azide (SA) to the reaction mixture. SA inhibits the transfer of electrons from cytochrome $\mathrm{a}_{3}$ to the final acceptor, oxygen, so that electrons cannot be passed.

\section{Material and Method}

1: Cervical dislocation (CD) euthanasia and isolation of mice organs

Six-week old male BALB/c mice were euthanized by cervical dislocation. The thumb and index finger were placed on either side of the neck at the base of the skull or a narrow, blunt instrument, such as the dull edge of a scissor blade, acrylic ruler or cage card holder, was pressed at the base of the skull. With the other hand, the base of the tail or the hind limbs were pulled quickly, causing separation of cervical vertebrae from the skull.

\section{2: Separation of mitochondria by cellular fractionation}

Cellular fractionation of mice homogenized liver, lung and kidney were accomplished through differential centrifugation.

\section{3: Extraction and Screening of andrographolide}

The plant, Andrographis paniculata, was collected from nursery. The leaves were shade-dried, followed by blowing in hot air oven for 30 minutes at low temperature and then powdered. The dried powder (100 gm) was subjected to extraction with $1200 \mathrm{ml}$ ethanol for $48 \mathrm{hr}$. The ethanol extract was collected, filtered \& concentrated in vacuum under reduced pressure and dried in desiccators. Employing thin layer chromatography (TLC), $5 \mathrm{ml}$ of the ethanolic leaf extract was put on each spot. A precoated plate of silica gel 60F254 (Merck) 
and mobile phase (chloroform: methanol: ethyl acetate $-8.0: 1.5: 1.0$ ) were used. The extracts, fractionated by TLC, were detected in UV radiation (Electronic UV Transilluminator, Quantum Scientific). The Rf of andrographolide was 0.58 .

\section{4 : Screening for enzyme inducing effect of andrographolide}

Different concentrations of andrographolide $(10-50 \mathrm{mg} / \mathrm{ml})$ were used for the screening of SDH activity. These concentrations were added with mitochondrial fractions (excised from liver, lung and kidney) DCIP and SA. The experiment was carried out with two separate controls: 1) no SA (ensuring normal electron flow through the respiratory chain together with electron flow to DCIP) and 2) no andrographolide (ascertaining positive control for normal optimum activity of SDH).

\section{5: Determination of SDH activity}

The reaction was measured at $600 \mathrm{~nm}$ using spectrophotometer. An electron acceptor was introduced, which accepted the electrons of $\mathrm{FADH}_{2}$ and got reduced. In order to ensure one way flow of electrons, the normal path of electron transfer, through the respiratory chain, was blocked using SA. It blocked the transfer of electrons from cytochrome $\mathrm{a}_{3}$ to molecular oxygen, bringing the entire process of electron transfer in the respiratory chain to a standstill. All the electrons generated from the oxidation of succinate then flowed to the introduced electron acceptor.

\section{Results \& Discussion}

SDH acceleration studies of bioactive compound andrographolide against mitochondrial fractions of kidney, liver and lung tissues are presented in Table - 1. The hastening effect of andrographolide on SDH activity in lung fraction was relatively more prominent than on SDH activity in mitochondrial fractions taken from kidney and liver. At $50 \mu \mathrm{g} / \mathrm{ml}$ concentration, it was $68.19 \%, 59.52 \%$ and $59.11 \%$ for liver, lungs and kidney respectively. During positive control (when no andrographolide was administered) SDH activity was found to be $38.50 \%, 57.66 \%$ and $54.63 \%$.

Table - 1 : Effect of Andrographolide on SDH activity in mitochondrial fractions of liver, lungs and kidney using Spectrophotometer.

\begin{tabular}{lcllllll}
\hline SDH activity & $\begin{array}{c}\text { Concentration of andrographolide }(\boldsymbol{\mu l} / \mathbf{m l}) \\
\text { Absorbance at } \mathbf{6 0 0} \mathbf{~ n m}\end{array}$ & & & & & \\
& Positive Control & $\mathbf{1 0}$ & $\mathbf{2 0}$ & $\mathbf{3 0}$ & $\mathbf{4 0}$ & $\mathbf{5 0}$ \\
\hline Mitochondrial fractions & 0.225 & 0.210 & 0.195 & 0.172 & 0.112 & 0.092 \\
Kidney & 0.210 & 0.190 & 0.180 & 0.165 & 0.095 & 0.085 \\
Liver & 0.305 & 0.265 & 0.211 & 0.192 & 0.173 & 0.102 \\
Lungs & & & & &
\end{tabular}

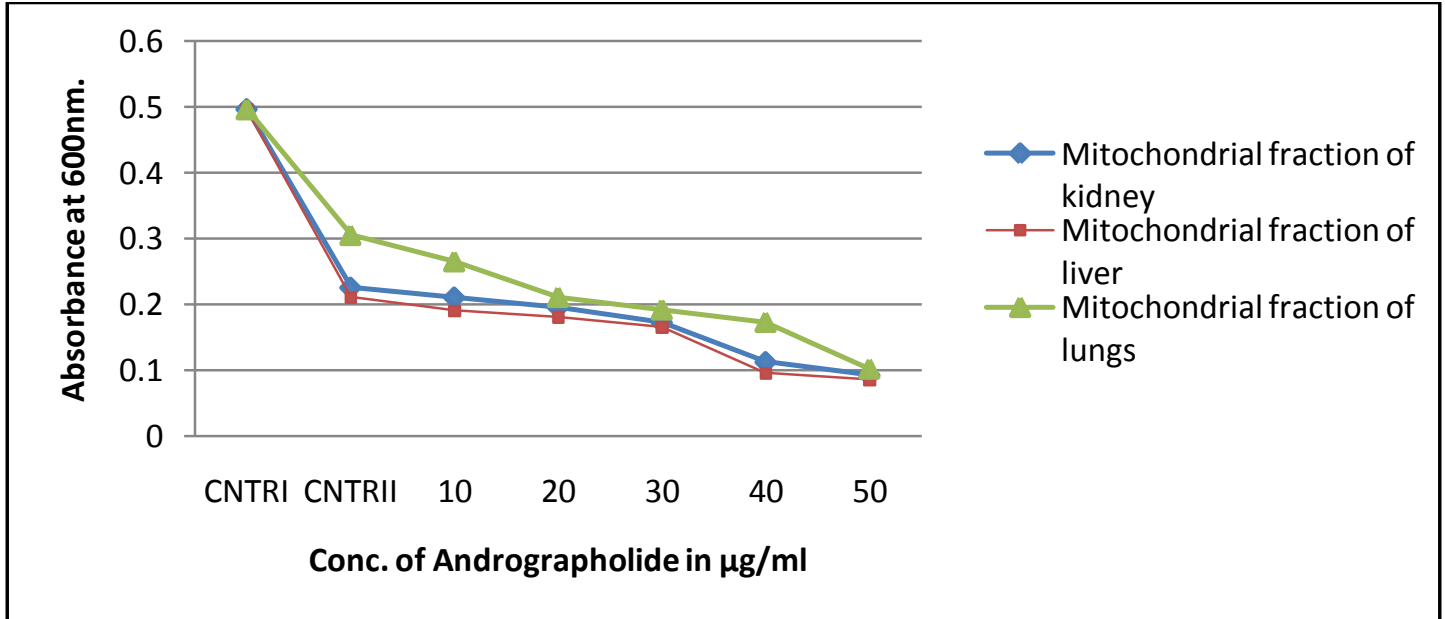

Fig - 1 : Effect of Andrographolide on SDH activity in mitochondrial fractions of liver, lungs and kidney. 


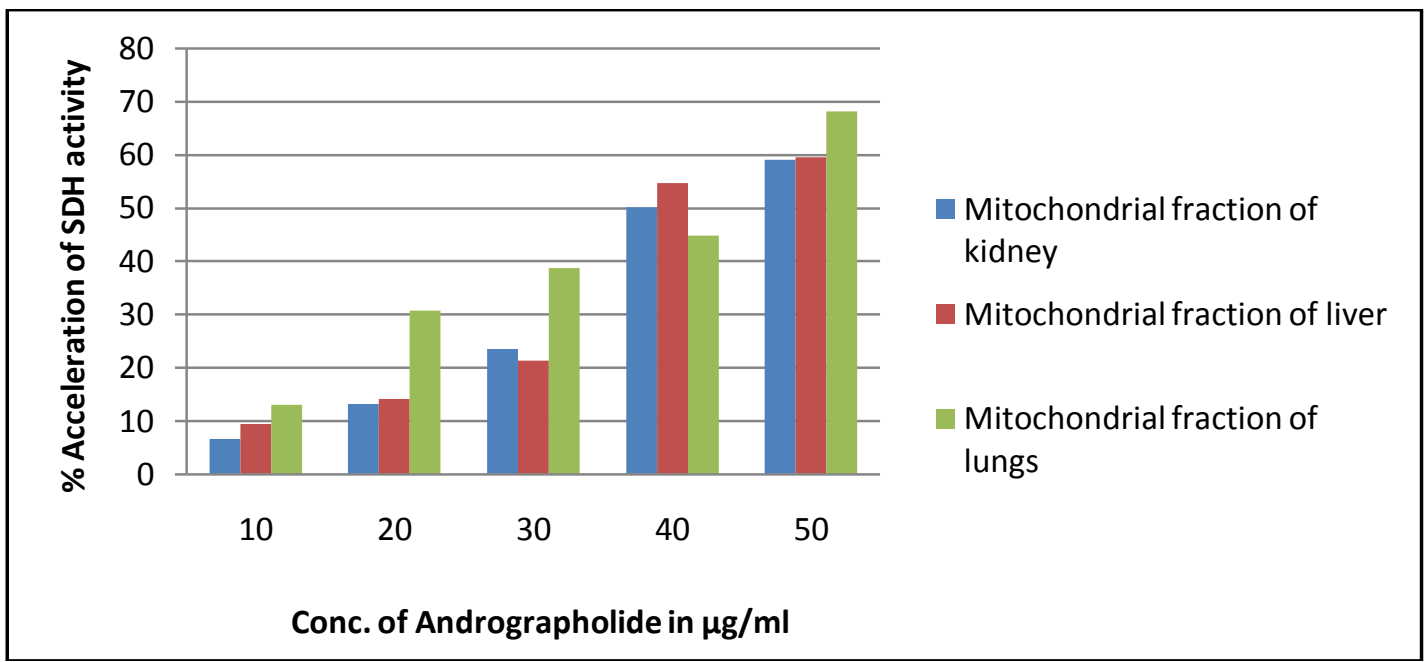

Fig - 2 : Percentage Acceleration in SDH activity

SDH apart from playing a central role in the Kreb's cycle and the respiratory chain, also outdoes other mitochondrial dehydrogenases owing to its exclusive redox properties. In association with ubiquinone, SDH represents a crucial antioxidant enzyme in mitochondria, controlling superoxides scavenging activity in its respiratory chain. Recent studies have revealed that SDH genes act as a tumour suppressor in humans (Tomlinson et al., 2002). During present study, andrographolide induced SDH activity against the mitochondrial fractions of liver, kidney and lung tissues showed substantive acceleration. The bioactive compound, andrographolide, is a herbal medicine and has been used in the treatment of diverse cellular and metabolic disorders including cancer. (Parfait et al, 2000).

\section{References}

[1]. Ackrell, B.A.C., Kearney, E.B. and Singer, T.P. (1978). Mammalian succinate dehydrogenase, Methods Enzymol, Vol. 53: 466-483

[2]. Agarwal V.S. (1997). Drugs plants of India. Ludhiana: Kalyani Publishers Vol. 1: 1.82.

[3]. Ahmad, M. and Asmawi, M. Z. (1993). Some pharmacological effects of aqueous extract of Andrographis paniculata Nees. International Conference on The Use of Traditional Medicine and Other Natural Products in Health Care (Abs), University Sains Malaysia, Malaysia, 122.

[4]. Anderson, S., Bankier, A.T., Barrell, B.G., De Bruijn, M.H.L., Coulson, A.R., Peron, I.C., Nierlich, D.P., Roe, B.A., Sanger, F., Schrieier, P.H., Smith, A.J.H., Staden, R., Young, I.G. (1981). Sequence and Organization of the Human Mitochondrial Genome, Nature Vol. 290: 457-465.

[5]. Alangaden, G. J., and Lerner, S. A. (1997). Clinical use of Fluoroquino-lones for the treatment of Mycobacterial Diseases. Clin. Infect. Dis., 25:1213-1221.

[6]. Berg, J.M., Tymoczko, J.L., and Stryer, L. (2007). Biochemistry, 6th edn. New York, W.H. Freeman \& Co.

[7]. Benning, M.M., Meyer, T.F., Rayment, I. and Holden, H.M. (1994). Molecular structure of the oxidized high potential iron-sulfur protein isolated from Ectothiorhodospira vacuolata, Biochemistry, Vol. 33: 2476-2483.

[8]. Bhatt, D.K. (2009). Modulation of tricarboxylic acid cycle dehydrogenase during hepatocarcinogenesis induced by hexachlorocyclohexane in mice. Experimental and Toxicological Pathology, Vol. 61(4): 325-332.

[9]. Chan, D.C. (2006). Mitochondria : Dynamic organelles in disease, aging and development. Cell, Vol. 125 (7): $1241-1252$.

[10]. Ernster, L. and Dallner, G. (1995). Biochemical, physiological and medical aspects of ubiquinone function. Biochem Biophys Acta, Vol. 1271: 195-204.

[11]. Parfait, B., Chretien, D., Rötig, A., Marsac, C., Munnich, A., and Rustin, P. (2000). Compound heterozygous mutations in the flavoprotein gene of the respiratory chain complex-II in a patient with Leigh syndrome. Hum Genet, Vol. 106: $236-243$.

[12]. Thunberg, T. (1909). Studien über die Beeinflussung des Gassustausches des überlebenden Froschmuskels durch verschiedene stoffe. Skand. Archiv Physiol., Vol. 22: 430-436.

[13]. Tzagoloff A., Akai A., Foury F. (1982). Assembly of the mitochondrial membrane system XVI. Modified form of the ATPase proteolipid in oligomycin - resistant mutants of Saccharomyces cerevisiae.

[14]. Tomlinson I.P.M. (2002). Germline mutations in FH predispose to dominantly inherited uterine fibroids, skin leiomyomata and papillary renal cell cancer. Nat Genet., Vol. 30:406 - 410.

[15]. Yankovskaya, V., Horsefield, R., Törnroth, S., Luna-Chavez, C., Miyoshi, H., Léger, C., Byrne, B., Cecchini, G. and Iwata, S. (2003). Architecture of succinate dehydrogenase and reactive oxygen species generation. Science, Vol. 299: 700 - 704. 